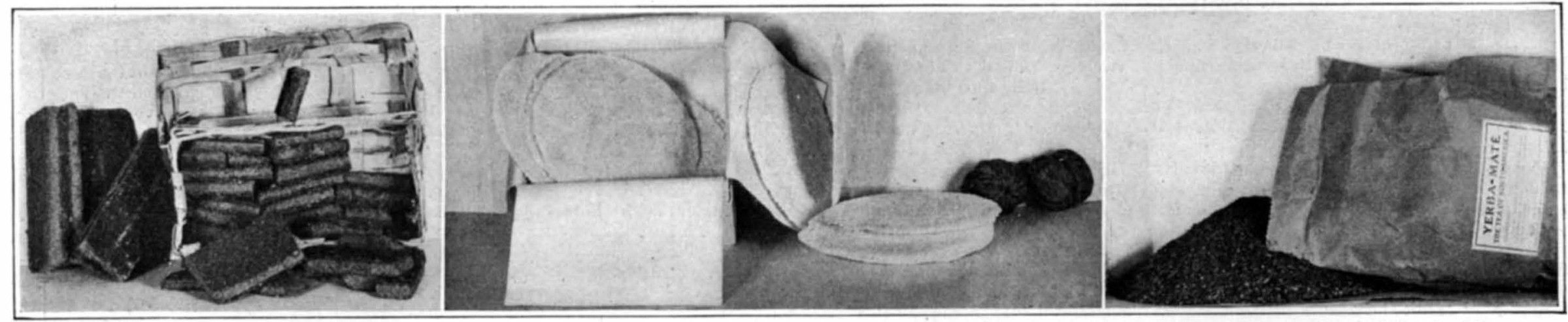

Left: Panocha bar- and tablet-sugar of South America, imported in many forms. Center: Cassava hard-tack bread disks, with the jumbo walnuts of Chile, ranging six inches in girth.

ea-table items from south of Panama

\title{
Latin Foods in Old New York
}

\section{Something Familiar for the Native of Any Quarter of the New World}

\section{By L. Lodian}

W ROM the tortillas and tamales of Mexico and Venezuela, the sun-dried meats of Uruguay and Argentina, the dried bananas of Central America, the yerba-maté of Paraguay and Brazil, to the cassava bread of Colombia and Ecuador, the crude-sugar cones of Peru and Cuba, the choice nuts of Bolivia and Chile - such are but a few of the foodstuffs of Latin America currently obtainable in New York City. There are more currently obtainable in New York City. There are more diverse South American edibles on daily sale in old to the south of us. Nor is this surprising.

A newspaper directory for 1920 lists more technical and class journals printed in Spanish within the boundaries of Manhattan than will be found in Buenos Ayres or Rio de Janeiro. These of course are chiefly concerned with the export business-or supposed to be. There are in particular a number of very creditable house organs printed in Spanish for circulation through the southern republics. Manhattan has also a HispanoAmerican institute the like of which exists in no other city of the new hemisphere, or even of Spain itself. In this metropolis of the new world will be found a greater variety of nationalities from the southern republics than anywhere south of the Rio Grande. Due to the presence of these people it is that there are imported to New York the various foodstuffs characteristic of each of the Latin countries. Obviously if we can buy in New York the major elements of the dietary of each of our southern neighbors, the totality of foreign products thus offered will be much greater than in one of the southern republics itself, which does not cater particularly to the tastes of visitors from the other side of the Andes. Of the many featureful and representative comestibles from the Latin table which the writer has purchased in the stores of New York, a few of the most striking are illustrated here

Your Latin-American must have his black coffee in small cups, sweetened with the crude panocha sugar. The difficulty, when he is sojourning abroad, consists in getting the sugar. This serves a triple purpose; it helps clarify the coffee, it of course sweetens the drink, and it imparts a certain smooth, semi-syrupy gusto to the beverage which seemingly only the Latin knows how to relish. The illustration shows this sugar in bar form, as imported in curious woven one-kilogram imogram containers of wood shavings a box de luxe for the peon. These are retalled at about half a dollar here in the countries of their origin they bring about onethird as much. The slab form is also obtainable at

the leading import houses but is less convenient for breaking up. Then there are the quaint little crude sugar canes. weighing one kilogram each; also the irregular chunks that result from loose packing in harrels, followed by a settling of the mass into a rocklike whole which can be dissociated only by the pick-axe. Another sugar obtainable in New York-if one is wise and lucky - is the palm product of the western coast A recent cousiunment in 300-pound barrels at

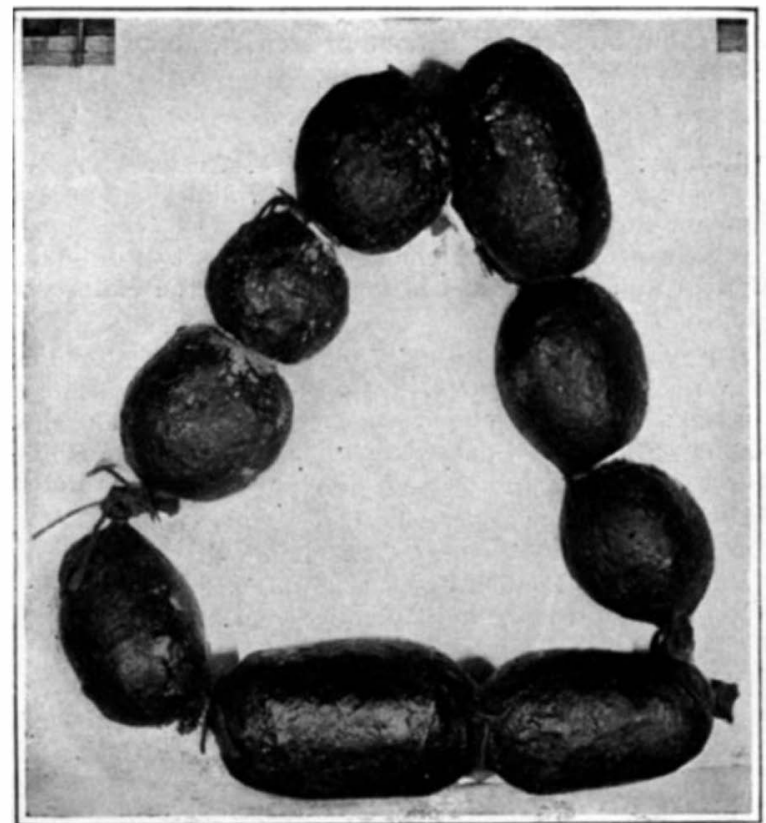

The morcilla of Latin America, a pork product preservable for years

eighteen cents was taken up as soon as announced. This is the only palm sugar of the western hemisphere, and is a most delectable sugar of honeyed fragrance. The color is sandy; whereas the palm sugar of India and other Asiatic parts and the Nile Region is brownish black of exquisite sweetness. It too is obtainable in New York and a few other American is clies rican cities intal stores.

The recent scandalous price of sugar, and the gluttony for sweets seen in the enormous candy consumption. have a moral : the use of table sugars should be prohibited in the manufacture of confections Meantime those hard-pressed to get any sugar at all might re member that in the Latin-American and other exotic colonies of Manhattan they can always get a little brown sugar of delectable flavor. The Arabic colonies have their raisin-, palm-, date-, karob-, manit-, and imf-sugars; the Japanese and Chinese their own particular versions; the Greeks their currant sugar Som of these, despite the long journey which they must make to reach the exiles whose demand creates the supply in America, are retailed at a lower figure than the granulated product from Cuba. During the last three years of recurrent sugar famine, the writer was never without sugar, though never hoarding it; he was always able to purchase a little among one or another of the Spanish-American or diverse other alien colonies of Manhattan.

The morcilla is a sustaining pork product from the south, which can be kept for years, becoming very hard on the outside yet softening up somewhat after paring off the rind. These parings, by the way, go into the stew-pot or soup-pot. The morcilla is ideal as a sustaining food for mountain travel; due to its fat content, it is probably the most heating meat product extant. It is put up in various forms-in bologna shape, in ball form, or in huge bladders which a man can scarcely lift. It is eaten just as it is, having been already doubly steam-cooked and subjected to prolonged smoking; or it can be served reheated, which develops the flavor appreciably.

Voyagers versed in travel-craft, and in need of a temporary makeshift drinking cup, are wont to scoop out the meat from a morcilla ball and use the skin as a vessel. Ground coffee or maté is put in, boiling water poured on, and all is merry. The heat wrinkles the membrane slightly, but it can be used about a score of times before it actually ruptures.

While familiar enough among the Latins of Manhattan, the South-American tea known as yerba-mate (ilex paraguayensis) has made slow progress as a beverage with Americans, although on sale in some local stores for the past three or four decades. It is a product of Paraguay and Brazil-that from the former country being in best repute among connoisseurs. It occurs in commerce as a finely comminuted leaf. and in the cup or pot, after adding boiling water, the tiny leaf flakes float for a couple of minutes exactly remi(Comtinued on page 1;i)

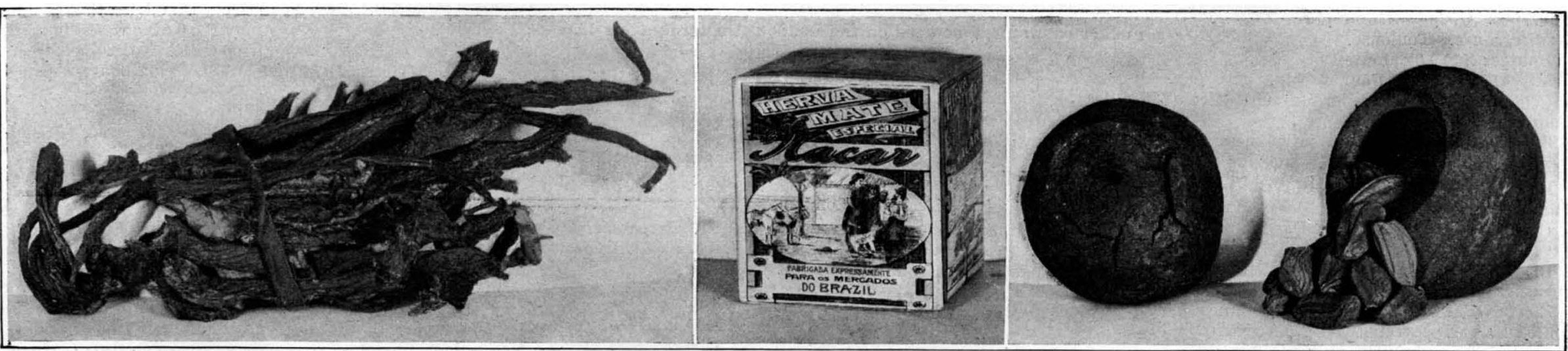

Left: Sun-dried unsalted strip-beef from the Plata; always dry and clean to handle. Center: Maté from Brazil ; the label shows the native way of sipping it through a tube from a gound. Right: The unbroken shell is a Brazil-nut pod; the other is the sapucaia nut from the upper Amazon

Food and drink from Brazil and her neighbors 
Shall We Have a National Trademark?

(Continued from page 175)

might eventually destroy the good will which they have built up abroad by long effort and at great expense.

It is to be observed that the objections stated are usually made against a national trade-mark in the strict sense of the term and not against the use of a legend in the form of a plain statement of origin, like "Made in U. S. A." In fact many of the most active opponents of the national trade-mark project have advocated the adoption of such a legend to be placed upon all goods exported, subject, perhaps, to certain reasonable restrictions A few months ago the British Merchandise Marks Committee, which had been appointed to consider various questions relating to trade-marks, reported that in its opinion no experience has yet been gained anywhere from which deductions as to the probable utility and effect of a national trade-mark for the United Kinglom or the British Empire could safely be drawn, and that in the absence of general agreement among the business men concerned there are grave objections to the adoption of such a mark. The majority of American business men would probably regard this as the sensible view to be taken in this country.

\section{Latin Foods in Old New York} (Continued from page 170)

niscent of the floating weed life of those tranquil village ponds of boyhood days The flavor is a quiet one-as of an Indian tea made with city-caught rain-water Everybody knows this peculiar taste.

Among some of the Latin cafés in Gotham you can get the infusion thus; or served in a gourd, with bombilla-a tube to imbibe the essence through, for by this method the maté really is an essence, not sufficiently diluted to be termed a beverage. Maté is imported in rawhide bales, in barrels, and in cases filled with onepound sheet-metal or cardboard contain ers, ready for the retail trade. The writer has been familiar with maté for the past three decades, both in the land of its origin and here, and has found it best when used as a blend with Asiatic teas. To Ceylon and Java teas, for instance, it imparts a suggestive suchong or kangu flavor-if your imagination is sufficiently active.

The maté tree is at the same time one of the most beautiful shade trees of tropical America; and many a Paraguayan and Brazilian rancher has only to strol into his well-shaded patio to cull a handful of leaves for his inevitable maté infusion. It is used with a little raw sugar - never any such superfluities as milk or cream.

Tasajo is the sun-dried meat from the abattoirs of Uruguay. Argentina, et al. It is obtainable either salted or unsalted the approved modern practice is to sun dry it quickly, without a particle of saltbut this modern practice is nothing really new, being only a copy of the oriental saltless curing of meats. Salting is partly destructive of the nutritive properties of meats, to the extent that, in desalting (as by water-soaking), nutritive juices are washed out and wasted. Perfect preservation can be attained without the presence of salt.

There is a huge annual import into Manhattan of tasajo-some two thousand tons - far beyond any local consuming needs. Yet it is almost all snapped up as soo as it enters. This is because the dealers in shipping supplies requisition the greater part for the use of the crews-so SouthAmerican tasajo is carried over the seven seas, mostly for the crews of sailing ships. It comes in many forms-strip, lariat, whole sides, paper-thin translucent sheets (one of its best varieties), as a coarse meal in sacks-the latter somewhat akln to a coarse Indian meat meal The strip is made from the sides, cut in one continuous length and zig-zagged over long lines to dength and zig-zagged over long in sun; the desiccation is (n) bright hard. Packed well its meaty odor, without even a sugcestion of taint. Opening a case, a n gestion of taint Opening a case, a novir might think it was so much rope. The lariat form of tasajo resembles so much narrow pulley-belting-since for space economy it is tightly coiled like belting. The great advantage of tasajo is that it never has a trace of bone or other waste in any of its forms, even bits of fat only occurring by chance. Eaten dry as it is-a common practice with the natives - tasajo is of good flavor, with appetizing meaty odor. But it chiefly figures in soups. Prior soaking in the same water in which it is later boiled will make it tender almost to the state of gelatine.

Kasabi is a native Indian word applied to a root legume common throughout tropical America from which the brea call A merica from which the breadstuf some fifty different names and spellings in its various local habitats, but the Haytian patronymic given and the anglicized cassava are the best known. This is the daily bread of millions all over Latin America. It is regarded as the original bread of the western hemisphere-the next oldest being the maize tortillas. Wheat bread is an introduction of modern times, as ages go, in the western hemisphere; while rye bread is unknown even yet south of the Rio Grande.

Cassava is in fact a bread hardtack. It has not a particle of sweetness, as the word cake sometimes used in designating it might suggest; but it has a slight potato flavor Many might pronounce it insipid, since salt or yeast or other leavening agents are never used in the baking. The color is usually a beautiful cream-white; the disks are always thin, and are baked in sizes ranging from six to twenty inches in diameter. The bread is at once nutritive and feebly aperitive, like whole wheat bread; hence its use in preference to any other bread by the aged among the natives. Cassava has been imported and sold in Manhattan-principally among the Spanish-speaking-for the past half century or more.

Little known nut wares from SpanishAmerica are the sapucaia nuts from the Amazon and Orinoco. These are about the size of Brazil nuts, but with wrinkled shells. The nut meat has a flavor that combines those of sweet almonds and filberts. It is one of the most economically worth-while nuts of the globe. It is sometimes called the nut of paradise, in reference to the primeval character of the upper Amazon forests where it originates. The jumbo walnuts of the west coast are sometimes so big that the measuring tape reveals a girth of six inches, more or less. These huge nuts are always choice and meaty. The empty shells are sometimes hinged with a small fragment of thin leather glued on, and thus used for tobacco pouches, coin purses, etc.

The singu, or littie baby cocoanuts from Chile. no bigger than nutmegs. yet with the characteristic three eyes and half a thimbie full of milk, are worthy of passing mention.

There is too a big import of luscious tropical fresh fruits in season-as the custard apple, eaten with a spoon; the mango; the sapodilla; the guava, for preserving; green cocoanuts with a beautiful glossy flush, imported for their distilled water-like content, a most refreshing drink; and some two-score other fruity delectables.

In fact, no visitor to Manhattan from any corner of South or Central America or the West Indies need feel that he is a stranger in a strange land so far as his food is concerned; for whatever his country, he can find in New York most of its good things to eat.

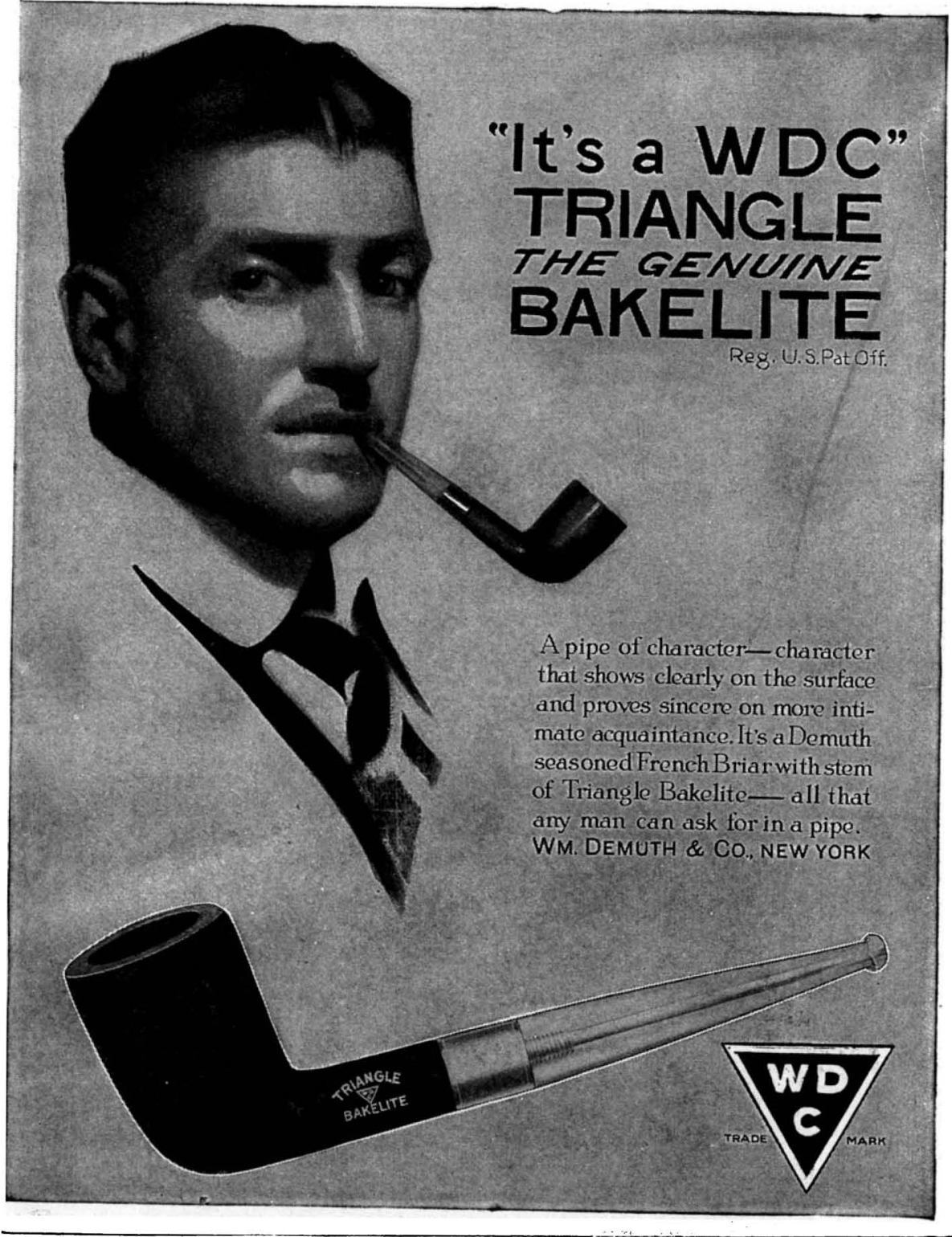

\section{Have You Something We Could Manufacture?}

A client, producer of Hollow Steel Forgings, Hot and Cold Rolled Strip Steel, Billets and Slabs, is seeking to expand his production.

The plant, greatly developed during the war period in the manufacture of shells, includes an immense machine shop, ready to finish quickly and economically any article made from hollow forgings.

If you hold any invention as yet unmarketed which would be suitable for a mill with the above equipment to manufacture, our client will be glad to consider it.

Also, if you are manufacturing any finished article which includes the use of hot or cold rolled steel, we will be glad to place you in communication with our client.

Communications addressed to this office will be placed in the hands of this client.

THE AITKIN-KYNETT CO. Advertising Agency

1328 Walnut Street Philadelphia, $\mathrm{Pa}$. 